\title{
Financial Fragility, Patterns of Firms' Entry and Exit and Aggregate Dynamics
}

\author{
Domenico Delli Gatti * \\ Gianfranco Giulioni ${ }^{\dagger}$ \\ Mauro Gallegati ** \\ Antonio Palestrini ${ }^{\dagger}$
}

june 2000

\section{Introduction}

Recent econometric investigation using longitudinal firms data (Davis, Haltinwanger and Schuh, 1996 ; Davis and Haltinwanger, 1996; Caballero et al., 1997; Stanca and Gallegati, 1999) shows that idiosyncratic factors affect the aggregate rates of change of output, investment and employment. Even similar firms within the same industry exhibit very different behavior at business cycle frequency. During an expansion (recession), when almost all industries grow (decline), a significant fraction of establishments decline (grow), and some exit (entry) the market. There is so much heterogeneity at the micro level that the usual approach to macroeconomics based upon the representative agent becomes questionable. Once we relax the representative agent hypothesis, fluctuations and cycles may emerge as the result of changes in the distribution of agents rather than the consequence of exogenous shocks to which a "representative" individual reacts, as in the standard literature on the business cycle. The framework of the "equilibrium representative firm", which represents the cornerstone of mainstream micro-founded macroeconomics thus becomes inadequate, and agents' heterogeneity (at least in the first two moments of the distribution: see Teräsvirta and Lundbergh, 1998) has to be considered.

\footnotetext{
*Catholic University, Milano, Italy.

** University of Teramo, Italy.

†University of Ancona, Italy.
} 
If the framework is linear, as most mainstream models assume, large fluctuations (i.e., of a size comparable to the empirical evidence) are produced by large shocks or a sum of small shocks. Since disturbances are characterized by zero mean this last case is ruled out, and the analysis of fluctuations has to be confined to that of great events (oil shocks, wars, and so). On the contrary, if sufficiently self-reinforcing non-linearities are introduced, small shocks may generate dramatic changes. But whenever a strong non-linearity is present, the "strong law of large numbers" does not work, and aggregation becomes a not a trivial matter (Rahn, 1985). The canceling out of idiosyncratic shocks is further rejected by empirical evidence and it is becoming more and more evident that the evolution of the cross-sectional distribution at individual level, determines aggregate changes at business cycle frequency.

If agents are heterogeneous, the propagation mechanism is affected by changes in the distribution of agents. In such a case, it is no longer true, as Lucas (1977) claims, that "business cycles are all alike" (see Zarnowitz, 1998). Whatever is the nature of the impulse (Temin, 1998), the propagation mechanism can make the difference, if it is large enough to amplify an impulse. Our modeling strategy, allows analyzing fluctuations due to the impulse-propagation mechanism in two ways. On the one hand, fluctuations may be due to allocative shocks, i.e. to idiosyncratic disturbances; on the other, aggregate changes are primarily generated by aggregate shocks, propagated and amplified by agents' heterogeneity. Moreover, financial fragility (which is the source of agents' heterogeneity and the propagation mechanism in this paper) may generate an endogenous cycle (see Delli Gatti, Gallegati and Palestrini, 1999). 'The combination of agents' heterogeneity and nonlinearities has relevant implications for aggregate fluctuations. In fact, the aggregate variables exhibit time varying elasticities to idiosyncratic and aggregate shocks, i.e. the impact of a shock will depend on the distribution of individual financial position.

According to Pigou (1928), who modified the Marshallian concept to adapt the tool of the representative firm to the Classical economics, it is an average or modal firm which is in equilibrium when the industry is in equilibrium, rather than a "purely statistical concept, a vector of averages" (Alchian, 1950: 127). According to Marshall, the representative firm is subject to the life-cycle hypothesis, and the birth-death process of industrial units which are implied by this view, allows the scholar to describe industrial dynamics. The concepts of short and long run themselves are closely correlated to the turnover process: the long run is in fact a period of time in which 
the entry of new firms produces an efficient distribution of the firms within the industry. Recent empirical analysis (Foster et al., 1998) shows that replacement of existing less productive plants with more efficient entrants, i.e. the entry-exit effect, dominates productivity growth. Similarly, Bernanke et al., 1998 emphasize the role of financial fragility during the cycle, which can be interrupted by an endogenous shake-out, determined by a non-linear financial accelerator, with possible domino effects due to bankruptcies.

In the same vein of Bernanke and Gertler (1989), Greenwald and Stiglitz $(1988,1990,1993)$ have developed a theoretical framework in which the supply decisions of the firm depend upon a measure of its financial fragility due to the presence of bankruptcy risk: the higher the firm's financial fragility i.e. the lower its net worth or equity base - the higher the risk of bankruptcy and the lower employment and output supplied. The theoretical set up by Greenwald and Stiglitz, therefore, explicitly allows for bankruptcy. They implicitly assume, however, that the number of firms is constant. This means that in case of bankruptcy the defaulted firm which exit the market is replaced by a newly born firm with the same features. In this case therefore, Greenwald and Stiglitz admit a entry-exit process but a very peculiar one: the turnover of firms, in fact, is constrained by construction to yield a constant number of existing firms. This is of course a restrictive and unrealistic assumption.

In this paper we relax this assumption and allow for an unconstrained turnover of firms. In particular we will allow for an endogenously determined flow of exiting firms (through bankruptcy) and model entry as a continuous stochastic process. This entry-exit process will affect the dynamics of the distribution of firms which are differentiated by the degree of financial fragility proxied by the equity ratio, i.e. the ratio of net worth to the capital stock. Our modelling strategy generates a system of stochastic difference equations which describe the dynamics of the mean and the variance of the equity ratio. The dynamics thus are affected by the entry of new firms and the endogenously generated process of firms' exit through bankruptcy.

The structural characteristics of the economy (such as the distribution of firms by size and degree of financial robustness, measured by the equity ratio, i.e. the ratio of net worth to the capital stock) and the aggregate variables (the capital stock, the equity base and aggregate output) can be interpreted as the outcome of a dynamic process which involves persistent financial heterogeneity and firms' turnover (birth and death of industrial units and changes in size and financial fragility of surviving units). All in all, 
changes in the mean and the variance of the firms' equity ratio are affected by the entry and exit of business units. ${ }^{1}$

The empirical evidence (Baldwin, 1995; Davis et al., 1996; Dosi et al., 1995) highlights several stylized facts a model should try to replicate. In particular:

- the entry and exit rates are highly correlated and occur both in the ascending and the descending stages of the business cycle (Dunne et al., 1998);

- firms are differentiated by their financial position and this kind of heterogeneity is persistent (Gallegati and Stanca, 1999);

- the rate of growth of a firm is a decreasing function of the size and financial robustness of the firm itself (Fazzari, Hubbard and Petersen, 1988). This implies that newly born, small and financially fragile firms grow more rapidly than existing large and financially sound firms. As a consequence, when firms become mature and reach a non negligible size and degree of financial robustness, the rate of growth levels off. The presence of a "life cycle" can be detected in empirical industrial dynamics (Klepper, 1996);

- the dynamic process displays a skewed distribution of firms (Sutton, 1997; Dosi et al., 1995);

- nominal and real shocks affect the equity base and, in the end, the growth and survival rate of each single firm (Judd and Treham, 1995);

- different degrees of financial fragility alternate during a cycle, abruptly interrupted by an endogenous shake-out with possible domino effects (Bernanke et al., 1998; Stanca et al., 1998).

This empirical evidence is hardly compatible not only with the Classical representative agent macroeconomic frameworks, but also with some features of non mainstream models without entry-exit. In particular, if the number of firms is kept constant, there exists a steady-state value to which the system returns (provided it is stable) after a shock. The analysis of fluctuations

\footnotetext{
${ }^{1}$ A similar approach, albeit in a different context, can be found in Campbell, (1997), who considers embodied technology instead of financial market imperfections.
} 
is therefore reduced to the analysis of the equilibrium return to a long run value, which is already set in the assumptions. ${ }^{2}$

In the search for a satisfactory way to model the evolution and persistence of heterogeneity over time and its role in the transmission and amplification of shocks, we have put forward a simple model (Delli Gatti, Gallegati and Palestrini, 1999) with imperfect capital markets along the lines of Greenwald and Stiglitz (1993; GS hereafter), which is summarized in section 2. In section 3 , we show how the model can be modified in order to allow for firms' entry and exit and illustrate its dynamical properties. Section 4 is devoted to some simulations. Section 5 concludes.

\section{The Model}

A large number of firms produce a homogeneous good using a constant return to scale technology whose unique input is capital (instead of labor as in GS). The production function of the i-th firm is: $Y_{i}=\nu K_{i}$.

Firms differ according to their financial conditions. The financial robustness of a firm is proxied by the equity ratio, i.e. the ratio of its equity base to capital $a_{i}=A_{i} / K_{i}$. The equity ratio can be conceived as a continuous random variable, whose pdf and cdf will be indicated by $f($.$) and F($. respectively.

As in GS, firms sell their output at an uncertain price. The individual selling price $P_{i}$ is a random variable with expected value $P$,i.e. the market price, and finite variance. Therefore the relative price $u_{i}=P_{i} / P$ is a random variable with expected value $E\left(u_{i}\right)=1$ and finite variance. Moreover, as in GS, the firm is rationed on the equity market but has unlimited access to credit: at the (exogenous) rate of interest $r$ the firm can obtain all the credit it needs to finance production. Debt commitments are $r\left(K_{i}-A_{i t-1}\right)$ where $A_{i t-1}$ is the net worth inherited from the past. We assume, for the sake of convenience, that dividends are equal to $r A_{i t-1}$. All in all, therefore, the cost of financing production is $r\left(K_{i}-A_{i t-1}\right)+r A_{i t-1}=r K_{i}$.

Because of the uncertain environment, firms may go bankrupt. Bankruptcy (which is costly) occurs if the financing costs are higher than revenues and the associated loss is higher than the net worth inherited from the past:

\footnotetext{
${ }^{2}$ The representative agent approach to fluctuations "cannot be seriously said to conclude that economic fluctuations are non-pathological, because it has already assumed just that", Hahn, Solow, 1995: 10.
} 


$$
r K_{i}-u_{i} Y_{i}>A_{i t-1}
$$

Substituting the production function into this condition and rearranging we get:

$$
u_{i}<\frac{r}{\nu}-\frac{A_{i t-1}}{\nu K_{i}} \equiv \bar{u}_{i}
$$

In other words, bankruptcy occurs if the relative price $u_{i}$ falls below the critical threshold $\bar{u}_{i}$. For the sake of simplicity we assume that the relative price is distributed uniformly on the interval $(0,2)$ so that

$$
\operatorname{Pr}\left(u_{i}<\bar{u}_{i}\right)=\bar{u}_{i} / 2=\frac{r}{2 \nu}-\frac{A_{i t-1}}{2 \nu K_{i}}
$$

The probability of bankruptcy is increasing with the interest rate and the capital stock (which in turn is linearly related to the level of activity) and decreasing with the equity base.

The expected profit is $E\left(\pi_{i}\right)=E\left(u_{i} Y_{i}-r K_{i}\right)=Y_{i}-r K_{i}$. The firm, however, incurs not only financing costs $\left(r K_{i}\right)$, but also capital adjustment costs $\left(C A_{i}\right)$, which are increasing with the rate of capital accumulation, and bankruptcy costs $\left(C B_{i}\right)$, which are increasing with output. In symbols:

$$
C A_{i}=\frac{\delta}{2} \frac{\left(K_{i}-K_{i t-1}\right)^{2}}{K}
$$

where $K$ is the average capital stock.

$$
C B_{i}=\left(\alpha_{1}-\alpha_{2} a_{i t-1}\right) Y_{i}
$$

where $a_{i t-1}$ is the equity ratio of the previous period, $\alpha_{1}$ and $\alpha_{2}$ are positive parameters.

In this setting, the problem of the firm is:

$$
\operatorname{Max} E\left(\pi_{i}\right)-C A_{i}-C B_{i} \operatorname{Pr}\left(u_{i}<\bar{u}_{i}\right)
$$


After substitution, we can reformulate the firm's problem as:

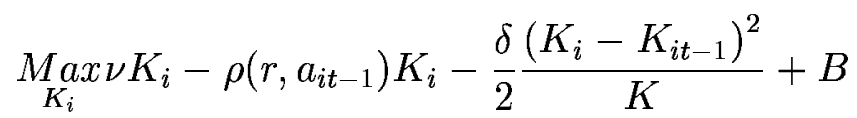

where

$$
\rho\left(r, a_{i t-1}\right)=r\left(1+\frac{\alpha_{1}}{2}-\frac{\alpha_{2}}{2} a_{i t-1}\right)
$$

is the bankruptcy cost augmented interest rate, which is increasing with the interest rate on bank loans and decreasing with the individual equity ratio, $B$ is a polynomial of parameters and predetermined variables independent of the capital stock.

Solving the problem yields:

$$
\frac{K_{i}-K_{i t-1}}{K}=\frac{1}{\delta}\left[\nu-\rho\left(r, a_{i t-1}\right)\right]
$$

It is easy to see that for each firm the rate of capital accumulation is an increasing function of its equity ratio, given the interest rate, which is uniform across firms.

The law of motion of the equity base of the i-th firm is:

$$
A_{i t}=A_{i t-1}+u_{i} Y_{i}-r K_{i}-\frac{\gamma}{2} \frac{\left(K_{i}-K_{i t-1}\right)^{2}}{K}
$$

Dividing by the individual capital stock and assuming that it is not too different from the average capital stock, i.e. $K_{i} \simeq K$, we can derive the law of motion of the equity ratio:

$$
a_{i t}=a_{i t-1}+u_{i} \nu-r-\frac{\delta}{2} \frac{\left(K_{i}-K_{i t-1}\right)^{2}}{K_{i t}^{2}}
$$

From (5) through aggregation we obtain the law of motion of the average equity ratio:

$$
a_{t}=\Gamma_{1} a_{t-1}-\Gamma_{2} a_{t-1}^{2}+\Gamma_{0} V_{t-1}
$$

where $\Gamma_{0}, \Gamma_{1}, \Gamma_{2}$, are polynomials of parameters, and $V_{t-1}$ is the variance of the distribution of the equity ratio at time t-1.From the definition of the variance at time $t$, we derive the following:

$$
\begin{array}{r}
V_{t}=\Gamma_{2}^{2}(\beta-1) V_{t-1}^{2}+2 \Gamma_{1} \Gamma_{0} \mu_{t-1}^{3}+4 \Gamma_{2}^{2} a_{t-1}^{2} V_{t-1}-4 \Gamma_{1} \Gamma_{2} a_{t-1} V_{t-1} \\
+\Gamma_{1}^{2} V_{t-1}+4 \Gamma_{2}^{2} \mu_{t-1}^{3} a_{t-1}
\end{array}
$$


where $\beta$ is a parameter capturing the kurtosis of the distribution, while $\mu_{t-1}^{3}$ is the third moment from the mean.

(6) and (7) is a system of two non linear difference equation in the state variables $a$ and $V$ which describes the evolution of the first two moments of the distribution of the equity ratio over time. It yields multiple steadystates whose properties depend on the configuration of parameters. Since the equilibrium properties of the system are jointly determined by the average equity ratio, as well as the second moment of the distribution, composition effects may be important in determining the business cycle.

Different configurations of parameters can give rise to the dynamic patterns which are typically analyzed in non-linear maps: convergence to one of the multiple steady-states, self-sustained business cycles, oscillations between cycles and fluctuations due to shocks and change of the distribution of the agents. ${ }^{3}$

In the case of self-sustained business cycles, the map shows a process of fluctuating growth due to capital accumulation Moreover, when agents' distribution changes, the amplification mechanism changes, and consequently the dynamical behaviour changes. In this context there is room for a redistributive policy which may decrease the variance of the equity ratio, thus producing a change in the dynamical behaviour.

\section{$3 \quad$ The entry-exit process}

It is well known - at least since Marshall - that firms experience a life-cycle. The birth-death process of industrial units implied by this view allows to describe industrial dynamics. The notions of short and long run are closely related to the firms' turnover. The long run is in fact an industrial configuration in which the entry of newly born firms yields an efficient outcome. This is the end point of a process of industrial dynamics characterized by a sequence of short run scenarios in which the market outcome is still inefficient.

We can easily and straightforwardly model the exit process in our framework which explicitly allows for bankruptcies: a firm goes out of the market if its equity ratio is so low that an adverse shock makes net worth become negative and pushes the firm into bankruptcy. When a firm goes bankrupt and leaves the market, aggregate potential output goes down.

\footnotetext{
${ }^{3}$ See Agliari et al. (1999) for a study of the dynamic properties of this type of system.
} 
The distribution of firms according to the equity ratio has to be modified to take into account this phenomenon. In each period, the density of the surviving firms' equity ratio $f\left(a_{i} \mid a_{i}>0\right)$ - i.e. the density of the firms' equity ratio conditional upon the event "positive equity ratio" - can be obtained from the original (unconditional) density $f\left(a_{i}\right)$ by means of a truncation. In other words, the density of the surviving firms' equity ratio $f\left(a_{i} \mid a_{i}>0\right)$ is a truncated distribution. . If $a_{i}$ is a continuous random variable, the following holds true:

$$
f\left(a_{i} \mid a_{i}>0\right)=\frac{f\left(a_{i}\right)}{\operatorname{Pr}\left(a_{i}>0\right)}=\frac{f\left(a_{i}\right)}{1-F(0)}
$$

where $F(0)=\operatorname{Pr}\left(a_{i} \leq 0\right)$, i.e. the distribution function evaluated at zero. From (8) follows that the expected value and the variance of the truncated distribution depend upon the original distribution. For the sake of simplicity, in the following we will assume that the distribution of the (unconditional) equity ratio is normal with mean $a$ and variance $V$.

Let $x$ be a continuous random variable distributed normally with mean $\mu$ and standard deviation $\sigma: x \sim N(\mu, \sigma)$. Let $\phi(z)$ and $\Phi(z)$ be, respectively, the pdf and cdf of the standard normal distribution $z \sim N(0,1)$, where $z=$ $\frac{x-\mu}{\sigma}$. We can define:

$$
\begin{gathered}
\lambda(z)=\frac{\phi(z)}{1-\Phi(z)} \\
\delta(z)=\lambda(z)[\lambda(z)-z]
\end{gathered}
$$

The function (9) is the hazard function. As to (10), it can be shown that: $0<\delta(z)<1$.

Let

$$
f(x \mid x>\bar{x})=\frac{f(x)}{\operatorname{Pr}(x>\bar{x})}=\frac{f(x)}{1-F(\bar{x})}
$$

be the density of the truncated normal distribution, where $\bar{x}$ represents the truncation point. Since:

$$
f(x)=\frac{1}{\sigma} \phi\left(\frac{x-\mu}{\sigma}\right) \text { and } F(\bar{x})=\Phi\left(\frac{\bar{x}-\mu}{\sigma}\right)
$$


we can rewrite it as:

$$
f(x \mid x>\bar{x})=\frac{\frac{1}{\sigma} \phi\left(\frac{x-\mu}{\sigma}\right)}{1-\Phi\left(\frac{\bar{x}-\mu}{\sigma}\right)}
$$

The first and second moments of the truncated normal distribution are (Green, 1997: 951):

$$
\begin{gathered}
\mu_{T}=\mu+\sigma \lambda\left(\frac{\bar{x}-\mu}{\sigma}\right) \\
\sigma_{T}^{2}=\sigma^{2}\left[1-\delta\left(\frac{\bar{x}-\mu}{\sigma}\right)\right]
\end{gathered}
$$

Since $\lambda(z)$ is positive and $0<\delta(z)<1$, from these expressions follows that the mean of the truncated distribution is higher than the original one while the variance is lower. This is consistent with the cleansing effect of recessions (see Caballero, Hammour, 1994; Reichlin, Siconolfi, 1998): during recessions the weakest firms leave the market as a consequence of bankruptcy, on average surviving firms have a higher equity ratio and their variance is lower.

Adapting the formulae above to our framework, the density of the truncated normal distribution of the surviving firms' equity ratio will be:

$$
f\left(a_{i} \mid a_{i}>0\right)=\frac{\frac{1}{\sqrt{V}} \phi\left(\frac{a_{i}-a}{\sqrt{V}}\right)}{1-\Phi\left(\frac{-a}{\sqrt{V}}\right)}
$$

Therefore, the mean and the variance of the surviving firms' equity ratio will be:

$$
\begin{gathered}
a_{T}=a+\sqrt{V} \lambda\left(\frac{-a}{\sqrt{V}}\right) \\
V_{T}=V\left[1-\delta\left(\frac{-a}{\sqrt{V}}\right)\right]
\end{gathered}
$$

As far as the entry process is concerned, in the literature it is modelled either as a purely stochastic process (Winter et al., 1997), or as an endogenous process (Hopenhayn, 1992), in which the number of entrants depends 
on the current profit margins. The empirical research has not been able to discriminate between the two views. According to Caves (1998: 1956) the evidence suggests a stochastic process, in which entrants are unsure about their success and "do not initially position themselves at a unique optimal size", i.e. they enter the industry at different sizes. Because of the informational imperfections which are pervasive in our setting, we assume that actual individual profits are private information. The potential entrant, therefore, has to infer the (average) profit margin by the number of incumbent firms, which signals the attractiveness of the market. Therefore we model entry as a stochastic process which is somehow affected by the number of firms already in the market. In other words, the entry process is not entirely stochastic: in particular, it depends upon industry performance, in terms of number of existing units ${ }^{4}$.

As Fazzari et al. 1988 show, small (large) firms have a high (small) propensity to invest out of internally generated funds. The aggregate propensity to invest is a weighted average of the propensities to invest of the different classes of firms. Since during the upswing small firms grow more rapidly than large ones, the weight of the former in the average has to increase. As a consequence, the aggregate propensity to invest can be modelled as a non linear increasing function of the flow of profits; i.e. a non-linear financial accelerator (Minsky, 1954; Bernanke and Gertler, 1989; Bernanke et al., 1998).

Moreover, the distribution of firms is skewed because of the interaction of firms' turnover and financial heterogeneity. This distribution is ipo-normal, since the financial position of entrant firms is normally distributed around the equity ratio, while firms in Ponzi positions are likely to exit and there is path dependency in the equity ratio dynamics (so that the successful firms are more likely to enjoy future success). In the end, the number of financially fragile firms increases and the death rate among the young firm (which are smaller by construction) is higher.

We also assume that the equity ratio of the entrants has mean $e$ and is independent from exit. The overall average equity ratio $(\bar{a})$ is a weighted average of the mean of the surviving firms' equity ratio $\left(a_{T}\right)$ and $e$. In other terms, we define $Q=N_{\text {entry }} / N$ the share of the entrants and, like above, we assume it is independent from the exit process. Moreover we assume that $Q$ is normally distributed, with mean $q$, and variance $\sigma_{q}^{2}$. Therefore the

\footnotetext{
${ }^{4}$ Simulations show that output fluctuations are less persistent if entry is modelled as a purely stochastic process.
} 
expected equity ratio is

$$
E(\bar{a})=(1-q) a_{T}+q e
$$

and the variance

$$
\operatorname{Var}(\bar{a})=\operatorname{Var}\left((1-Q) a_{T}\right)+\operatorname{Var}(Q e)+\operatorname{Cov}\left((1-Q) a_{T}, Q e\right)
$$

where

$$
\begin{gathered}
\operatorname{Var}\left((1-Q) a_{T}\right)=(1-q)^{2} V_{T}+a_{T}^{2} \sigma_{q}^{2}+V_{T} \sigma_{q}^{2} \\
\operatorname{Var}(Q e)=e^{2} \sigma_{q}^{2} \\
\operatorname{Cov}\left((1-Q) a_{T}, Q e\right)=-q e a_{T}
\end{gathered}
$$

It is worthnoting the very different nature of $Q$ in the case of a fixed as against a variable number of firms.

With a fixed number of firms $N_{t}=N=$ constant and

$$
N_{\text {entry }}=N_{\text {exit }}=\operatorname{Pr}(u<\bar{u}) N=\frac{\bar{u}}{2} N
$$

so that

$$
Q_{t}=\frac{\bar{u}}{2}
$$

which is a stable ratio.

In the case of a variable number of firms, instead, $Q$ may be unstable and the model behaves in a very different way. For example if the realizations of $Q$ are close to zero in a particular interval of time (recession), the overall average equity ratio will approach the behavior of the truncated mean i.e. it increases - while if the realizations are high (boom) the mean equity ratio fluctuates around a weighted average of the mean of the truncated distribution and that of the distribution of the entrants. Therefore the model behaves in an asymmetric way during recessions and booms. 


\section{Simulations}

Some dynamical characteristics of the model can be emphasized:

- the convergence to the steady state (if any) in the variable number case is slower than in the case where firms' population is constant. In fact heterogeneity stabilizes the dynamics but it also produces pathdependence, while dynamical adjustments have to trickle down the whole distribution of agents' positions before restoring equilibrium. An impulse transmitted to the system propagates in a non-linear way. Therefore, aggregate fluctuations are quite large while persistence is much higher because of firms' heterogeneity and turnover amplify the effects of small shocks (see Fisher, 1996; Williamson, 1996).

- Steady states are distribution-dependent: the long run equilibrium depends on the fundamentals and the mean and the variance of the stochastic variables $\xi$ and $Q$. The limit stochastic distribution depends on the properties characterizing the entry stochastic process, not only on the fundamental one. Long run equilibrium becomes a vague concept in this framework; since the steady state is not a single value, but rather a set, dynamics are not a trajectory but the evolution through time of the set, in which the stochastic number and equity ratios of the entrants affect long term values.

- The birth-death process modifies the financial fragility of the system differently during expansions and contractions, determining an asymmetric behavior of the cycle. Asymmetry derives from low probability of bankruptcy during a boom (skewness near zero) and high in recession (positive skewness). The pro-cyclical entry process (in levels) emphasizes asymmetry because of low realizations during recessions.

In order to illustrate some qualitative properties of the model, we performed several computer simulation. ${ }^{5}$ The aggregate dynamics is non-standard since the cyclical phases vary according to frequency, amplitude and timing. Simulations show that the equity ratio is strongly anti-cyclical and leads

\footnotetext{
${ }^{5}$ We used the Gauss program to run the computer simulations: Gianfranco Giulioni designed the program. Different parameter values (we used values producing convergence in the model with fixed number of firms) have been applied without affecting the basic qualitative results.
} 
the cycle, while its standard deviation is weakly pro-cyclical leading the cycle. On the aggregate, the number of firms is strongly pro-cyclical while the exit process is weakly pro-cyclical; even if the birth rate and the death rate are comparable, during an expansion (contraction) the difference is positive (negative).

When the rate of firms' birth rises, and their share on the total population of existing firms is small, the average equity ratio and its standard deviation change. In particular, they rise (fall) when the net difference between entry and exit is negative (positive) or the weighted ratio of the entrants is smaller (greater) than the actual one, giving rise to an endogenous non-linear relationship between the birth-rate and the equity ratio.

The increase of the equity ratio reduces the number of bankruptcies, so that the death rate decreases and the number of operating firms rises. A self-reinforcing process takes place: as the number of firms rises, the birth rate increases, negatively affecting the equity ratio and its standard deviation while, at the same time, output is booming. The ensuing increase of financial fragility makes the death rate to increase: both the standard deviation and the average equity ratio decrease, while the total number of firms goes down. The birth rate goes down, further deteriorating the financial conditions and output: only after a further depression the financial conditions improve, inverting the trajectory. Because of the stochastic nature of firms' turnover and the composition effect, the cyclical phases change in length, deepness, and timing, and the relationships between aggregate output changes and financial fragility changes from cycle to cycle too. ${ }^{6}$

Figures 1-3 show the paths of aggregate output, the average equity ratio and the standard deviation. The changes in financial fragility lead the output dynamics, i.e. the number and the market composition of various financially characterized firms. We borrow from Minsky, the taxonomy of industrial units according to their degree of financial fragility and adapt it to our context. A hedge unit has an equity ratio high enough to rule out any risk of bankruptcy. A speculative unit is more financially fragile (has a lower equity ratio) than a hedge unit but is still lingering on the threshold of survival. A Ponzi unit is postponing bankruptcy as long as it can access credit in order to reimburse the preexisting debt. A "normal" shock - to be

\footnotetext{
${ }^{6}$ This self-reinforcing mechanism gives rise to a non-linear relationship which exacerbates the amplitude of the fluctuations. Let's note that stochastic entry does not change the qualitative behaviour of the model, but persistence and amplitude of fluctuations are less evident.
} 


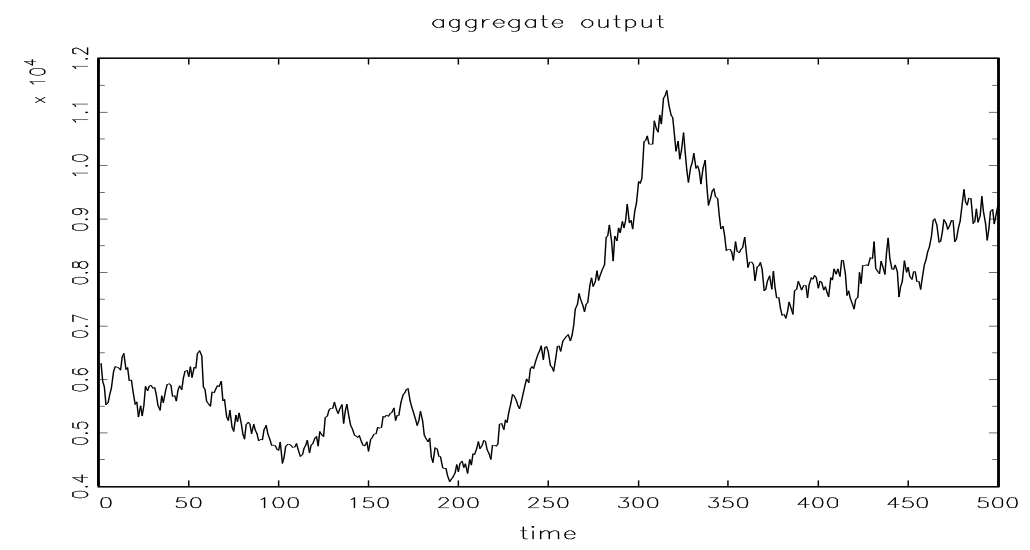

figure 1

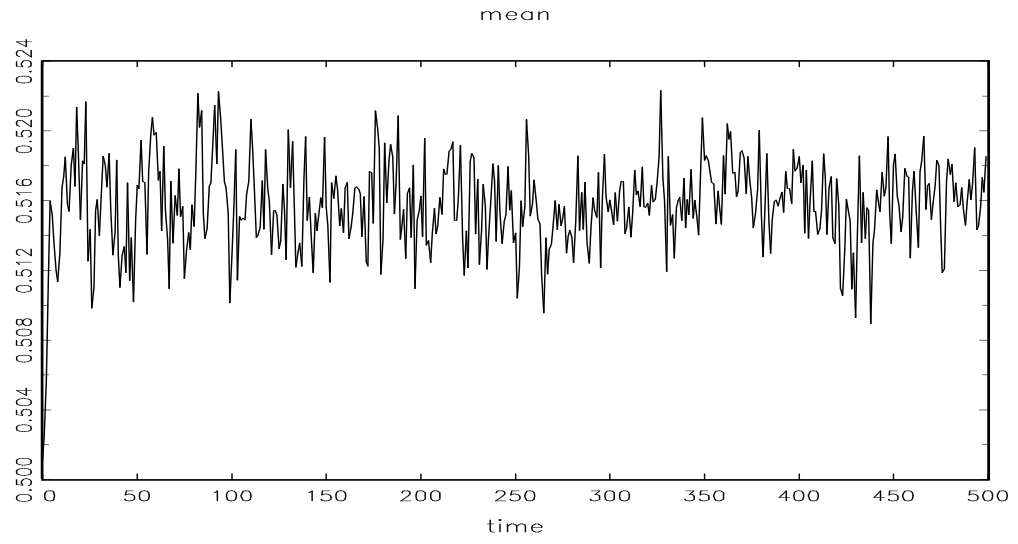

figure 2 
defined more precisely later - leads a hedge unit to become speculative, a speculative unit to become Ponzi and a Ponzi unit to go bankrupt. In line with the empirical evidence, speculative firms are more likely to enter the market than hedge ones. As figure 4 shows, the percentage of firms with respect to the financial position changes during the cycle.

In particular, the ratio of the number of financially fragile (speculative and Ponzi) firms to the number of hedge firms increases (decreases) during the upswing (downswing). Figures 5, 6, 7 and 8 show that large-size (mediumsize) (small-size) firms are generally financially hedge (fragile) (Ponzi) and their investment activity is generally a-cyclical or moderately pro-cyclical (strongly pro-cyclical) (weakly pro-cyclical).

We may also note that the birth and the death rate are strongly correlated (see figures 9-10, the variance of the firms' growth rate decreases with age (similar evidence for the US manufacturing sector has been found by Dunne et al., 1989), while the bankruptcy rate also declines with the age.

For the sake of exposition, we identify six phases of the business cycle from trough to peak: tranquil era, financially hedge phase, financially fragile boom, speculative recession, safe recession and hedge depression. Even if their periodicity, amplitude and frequency are irregular, and expansions last longer than contraction, each phase is led by a change in financial fragility which determines output behavior (see table 1). Business cycles are all alike in the sense that they are financially-determined: impulses of different nature cumulate with the heterogeneous setting, giving rise to erratic and complex dynamical behavior.

\begin{tabular}{|c|c|c|c|c|c|c|}
\hline & output & equity ratio & variance & birth & death & popul. \\
\hline tranquil e. & up & up & down(up) & low & high & const. \\
\hline hedge p. & up & stable & stable & mod. & mod. & incr. \\
\hline fragile b. & up & down & down & v.high & high & boom \\
\hline specul.r. & down & (up)down & up & high & v.high & falling \\
\hline safe r. & down & stable & stable & mod. & mod. & falling \\
\hline hedge d. & down & up & up & low & low & falling \\
\hline
\end{tabular}

Table 1

Let's describe the endogenous dynamics of a "business cycle". At the bottom of the cycle (tranquil era), the number of existing firms reaches a minimum 


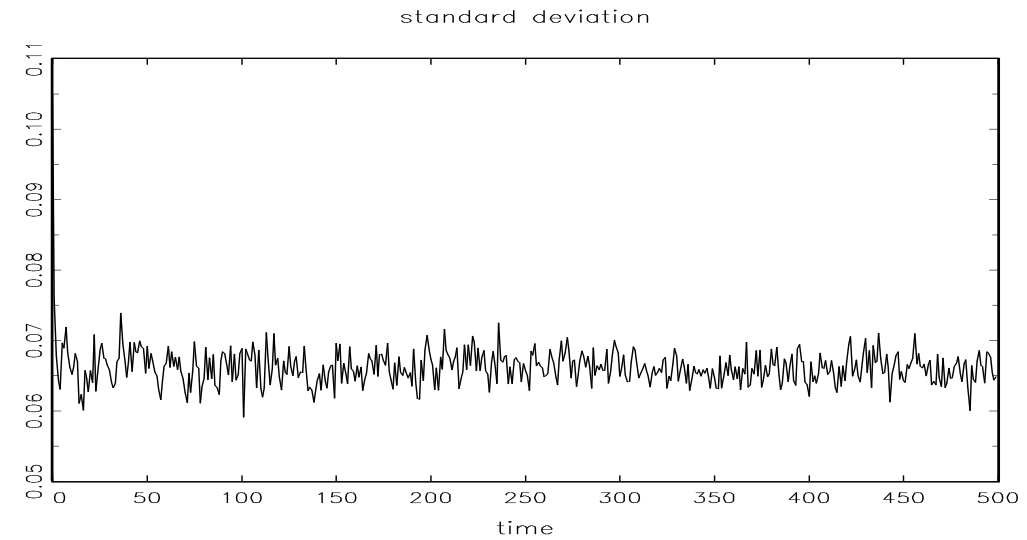

figure 3

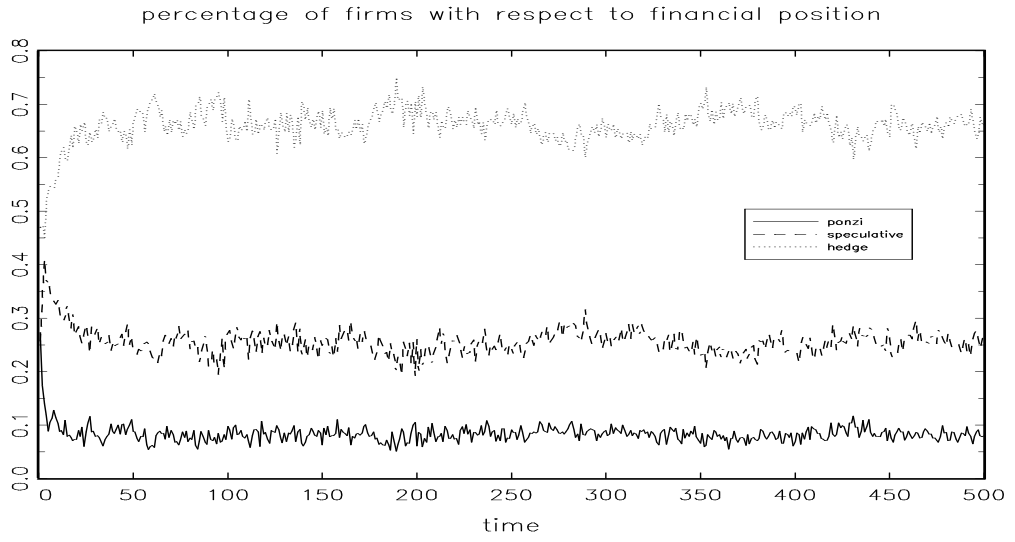

figure 4 
number of firms with respect to financial position

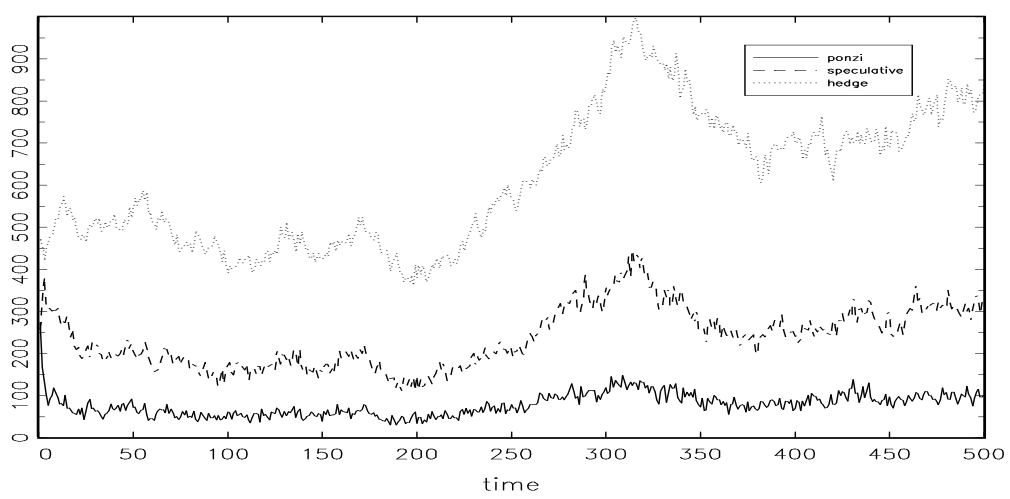

figure 5

percentage by size of hedge firms

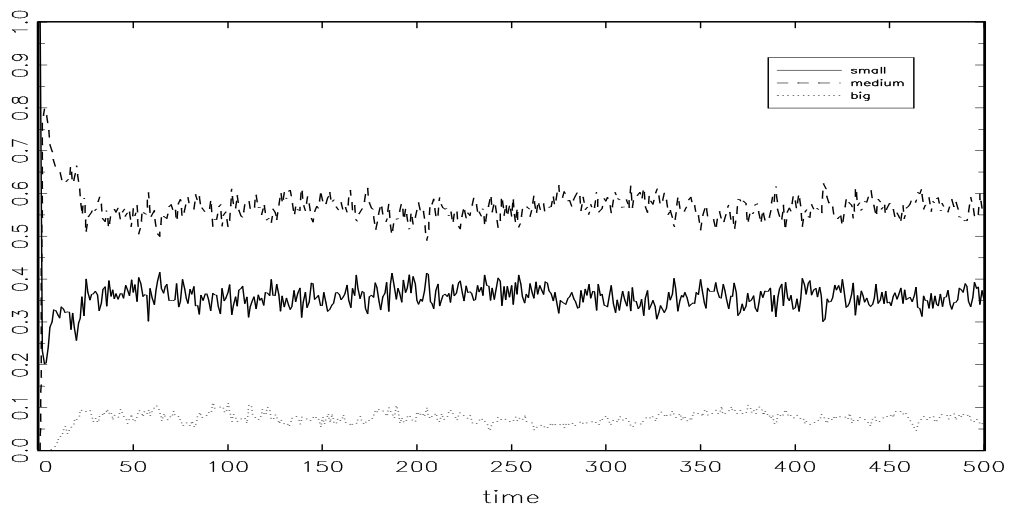

figure 6 


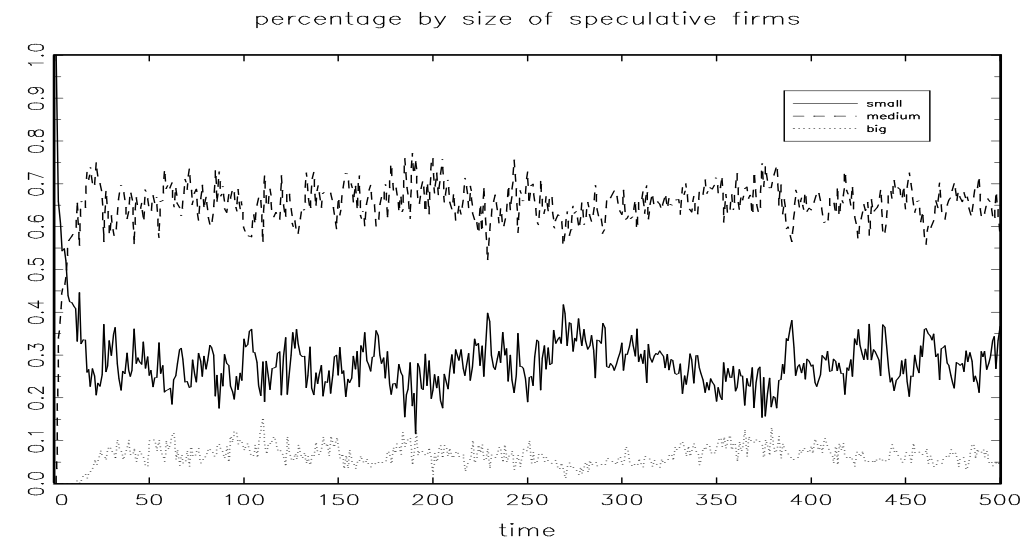

figure 7

percentage by size of ponzi firms

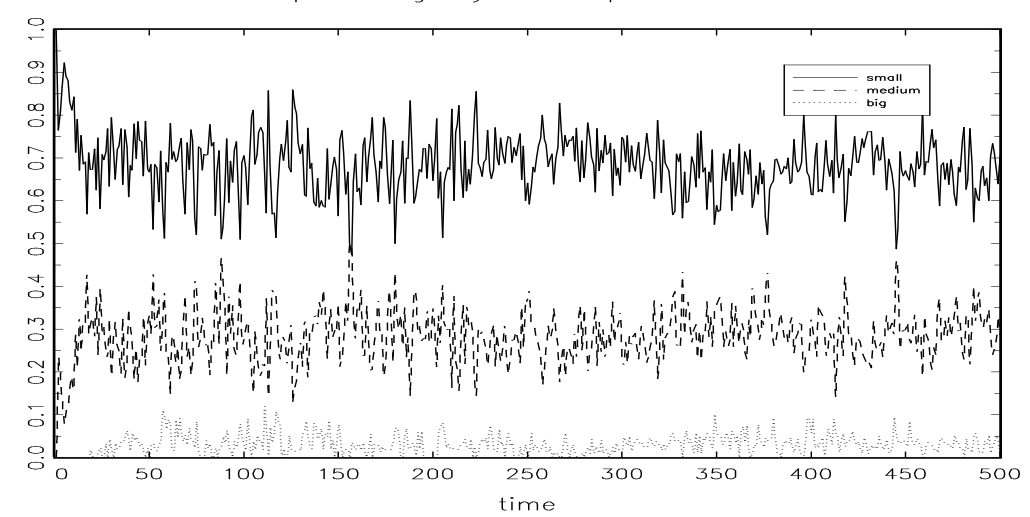

figure 8 
Number of entry

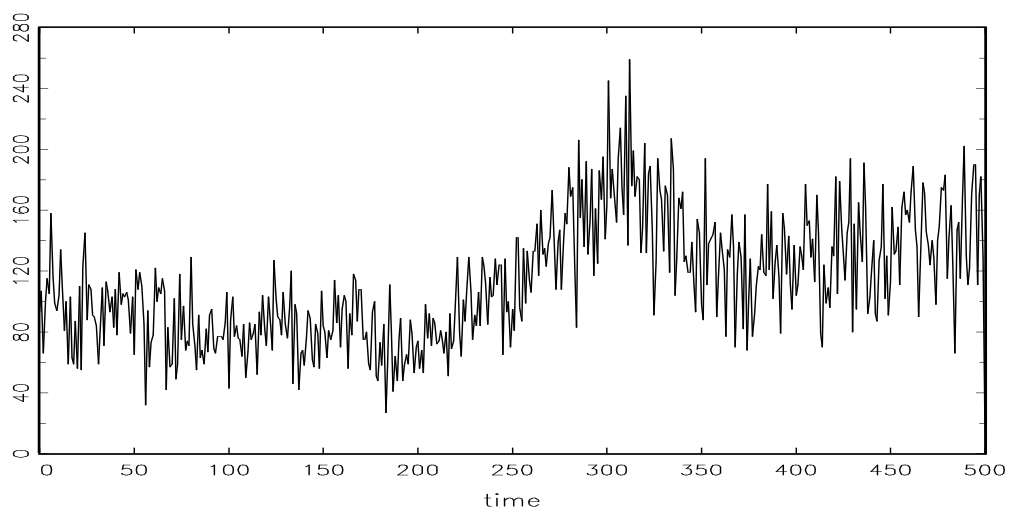

figure 9

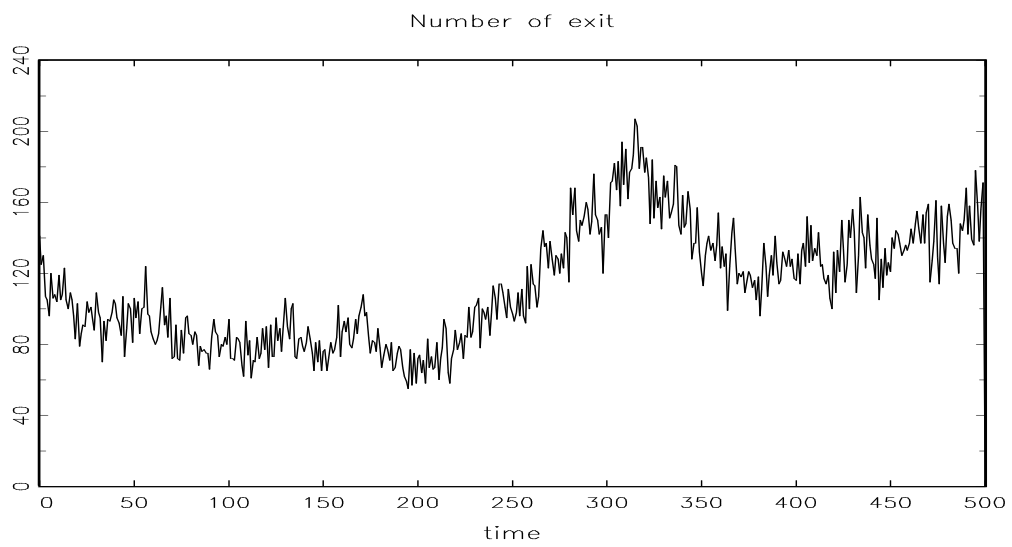

figure 10 
since the death process clears up the market by eliminating the more financially fragile firms: therefore, the equity ratio rises and its variance decreases reinforcing the financial stabilization (see firms' distribution in figure 11). This process is characterized by large fluctuations of the financial indicators because of the very high turnover which follows a downturn. Since firms' balance sheet become more robust, output and profits increase, while debt commitments become lighter. This scenario describes a virtuous circle in which the growth of investment and profits is paralleled by a decline in the stock of debt. Phases of "financially hedge" expansion coincide with the intermediate phases of a business cycle, since there are not sensitive changes in either the equity ratio and its standard deviation (see figure 12). In this phase, profits increase more than or in line with debt commitments, so that the equity ratio fluctuates around a stable value while its standard deviation is more heavily affected by firms' entry and fluctuates to a considerable extent.

This scenario does not go on forever. Positive profit opportunities attract new firms whose investment policy is very aggressive, their recourse to external funding is massive and this drives up aggregate debt, which eventually determines the transition to the following period: the "financially fragile" expansion. In this period, debt commitments become greater than profits, balance sheet deteriorate and this leads the endogenous downturn of the business cycle. Firms' balance sheets keep deteriorating, since debt accumulation rises faster than profits, which still continue to rise while the equity ratio collapses (figure 13). ${ }^{7}$

The financial crisis which follows is characterized by a fall in the flow of profits (firms invest to a lesser degree than during the previous period) while the stock of debt still rises. Right after the upper turning point, during the "speculative recession", the equity ratio increases, while the standard deviation has mixed behavior.. The decline of profits increases the firms' mortality rate, thus depressing output, so that external finance demand goes down. The flow of profits still shrinks more rapidly than the need for finance but at

\footnotetext{
${ }^{7}$ If euphoria comes in, then the dynamics become unstable and policy intervention has to be adopted (Minsky, 1986). Euphoria sets in as a contagious phenomenon which may affect system stability. It is not, per se, the causa causans of fluctuations but if it hits the system when the financial environment is fragile, the balance sheet position of most of the firms keep on deteriorating. Firms' bankruptcies may spread over the system (Fisher, 1933), and when the banking system is involved (Keynes, 1931), a massive collapse of output follows.
} 
a reduced pace with respect to the previous phase. Firms' balance sheets are still unbalanced and speculative financing situations are widespread (figure 14). Investment demand has to fall further to increase the financial soundness. A vicious circle of debt depression sets in: the decline in investment expenditure is a virtue for each single firm since its balance sheet was deteriorating, but if each firm reduces the demand for investment, aggregate demand and profits collapse (Keynes, 1931) rising the stock of debt to avoid bankruptcy (they run into Ponzi financing). ${ }^{8}$ When bankruptcies become less pervasive and the turnover is still negative, the equity ratio and its standard deviation stabilize (at a lower level with respect to the analogous intermediate stage of the expansion) during the period of "safe recession" (figure 15). The lower turning point of a cycle is led by a rise of the equity ratio and its standard deviation (which reaches a maximum). This costly process (which is faster than the expansion since the different birth-death rate) comes to an end when the ratio of debt commitments to profits starts decreasing in the hedge depression. Balance sheet configuration becomes hedge, even if profits and income continue to fall but still to a lesser degree than debt whose fall is very steep. At the end of the robust depression investment becomes greater than saving, a turning point in the business cycle occurs and a new recovery sets in; during the downturn, the average age and size of firms increase, while the financial positions become more robust (figure 16).

\footnotetext{
${ }^{8}$ To prevent the collapse, fiscal policy may act in an expansionary way, setting a floor (Delli Gatti et al., 1996) to sustain profits. The efficacy of monetary and fiscal policies is asymmetric: a tight (expansive) monetary policy immediately (slowly) prevent unstable behaviour (helps economy to recover) during a booming phase (via the lender of last resort mechanism).
} 


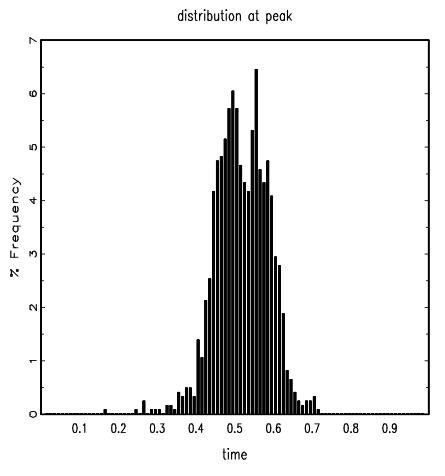

figure 11: period 283

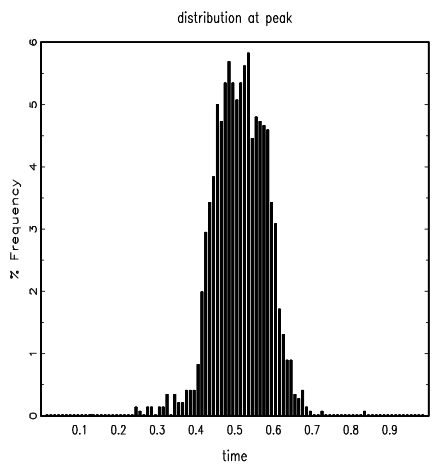

figure 13: period 309

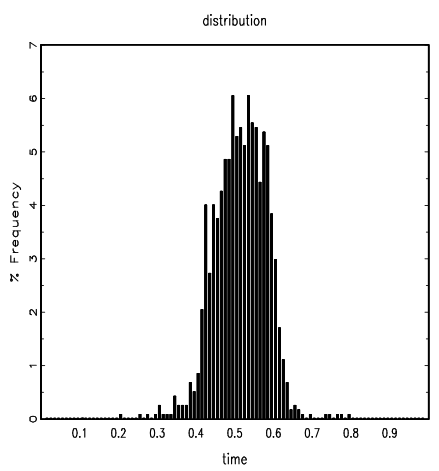

figure 15: period 346

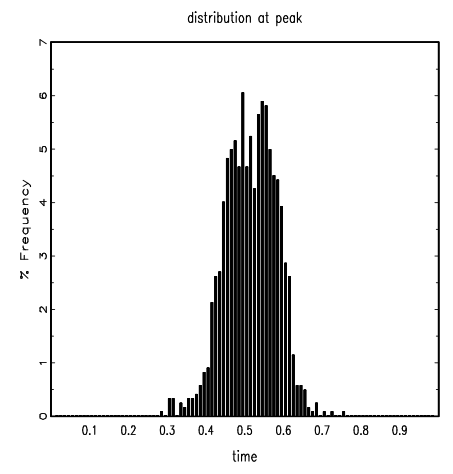

figure 12: period 292

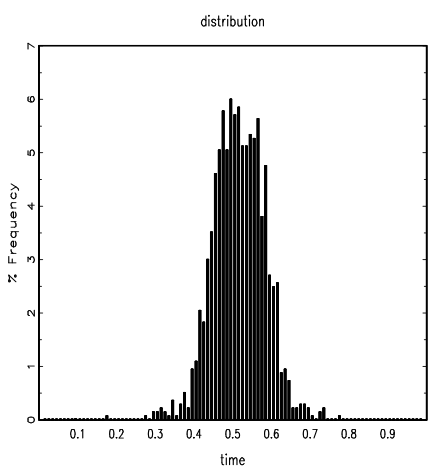

figure 14: period 336

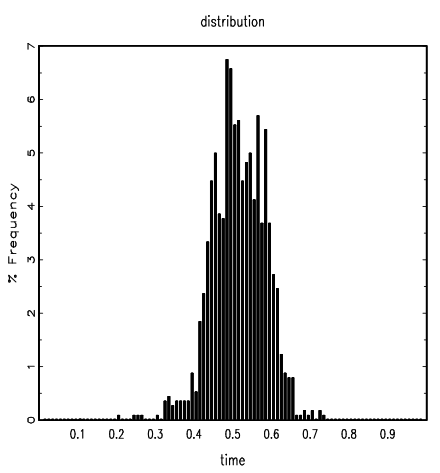

figure 16: period 358 
It is worth emphasizing the effect of monetary policy (and of nominal shocks in general) on fluctuations. In particular, tight (cheap) money rises (lowers) the rate of interest, affecting the firms' surviving rates (see the bankruptcy condition). Since there is not any more a one-to-one replacement of defaulted firm and entry is stochastic, the turnover of firms has a permanent effect. Furthermore, let's note that policy has path dependent effects: policy interventions which affect the balance sheets of the agents, cannot be reversed by opposite policy measure. Agents who have suffered losses because of increased debt burdens are not going to restore their previous balance sheet position because of open market operation.

Business cycle amplitude may change because policy sets in, thus avoiding large fluctuations to happen (as Hicks, 1950). In this context, each and every policy intervention affects initial conditions and changes the dynamical behavior (see Minsky, 1954, 1957; Delli Gatti et al., 1996), i.e. their frequency, because of its inner non-linearity. In this paper, with firms's turnover, a policy intervention may affect the death-birth process by affecting fluctuations and the steady state positions. Each cycle may be read as unique phenomenon with respect to its amplitude and frequency, as well as the sequence of different phases. Nevertheless, we believe a common aspect may be pointed out in the balance sheet position of the agents which lead and affect the dynamical behavior of the economy: fluctuations and cycles may emerge as the result of changes in the distribution of agents rather than the consequence of exogenous shocks to which a "representative" individual reacts, as in the standard literature on the business cycle.

According to the impulse-propagation approach to fluctuations small shocks may lead to large fluctuations once a sufficiently large amplification mechanism is activated. If agents are heterogeneous, the propagation mechanism is affected by changes in the distribution of agents. Whatever is the nature of the impulse, what really matters is the propagation mechanism. According to such a view, equilibrium is not a "natural" state but a distribution of states over time. Fluctuations must be conceived as the result of the interaction of different individuals, rather than the result of the reaction of identical individuals to an exogenous shock. In our setting a shock will trickle down across the whole distribution of agents modifying in such a way aggregate behavior.. If composition effects are large enough, they may produce very different effects depending on their size, i.e. the response of the system to the same shock changes over the business cycle. Different variances should in fact imply different response to the same impulse. 


\section{Conclusions}

In this paper, extending the framework originally put forward by Greenwald and Stiglitz (1988, 1990, 1993), we have developed a theoretical framework in which the financial conditions affect the capital accumulation decisions of the firm. Greenwald and Stiglitz explicitly allow for bankruptcy but they implicitly assume that in case of bankruptcy the defaulted firm which exit the market is replaced by a newly born firm with the same features. In this paper we relax this assumption and allow for an unconstrained turnover of firms. In particular we will allow for an endogenously determined flow of exiting firms (through bankruptcy) and a stochastic flow of entrant firms.

This entry-exit process will affect the dynamics of the distribution of firms which are differentiated by the equity ratio, i.e. the ratio of net worth to the capital stock. Aggregate variables (the capital stock, the equity base and aggregate output) can be interpreted as the outcome of a dynamic process which involves persistent financial heterogeneity and firms' turnover. All in all, changes in the mean and the variance of the firms' are affected by the entry and exit of business units.

We perform numerical simulations to study the interaction of changes in financial fragility and output dynamics. It turns out that changes in financial conditions play an important role in determining output fluctuations. The ratio of financially fragile (Ponzi and speculative) firms to hedge units increases during the ascending phase of the business cycle as predicted in Minsky's financial instability hypothesis. We may also note that the entry and exit rates are strongly correlated, a prediction which is broadly consistent with the empirical evidence for advanced market economies.

\section{A Appendix}

In this appendix we describe briefly the simulation.

First of all, it's necessary to specify the way a firm enter the market. We give a new firm its own equity ratio drawing from a normal distribution with mean 0.5 and standard deviation 0.1 . We recover the levels of nominal equity base and Capital in the following way. For the equity base we assume that a firm entering the market is small. We classify firms with respect to their size according to the level of their nominal equity base: less or equal to 30 the firm is small, between 30 and 60 the firm is medium and more than 60 
the firm is big. Thus we set the nominal equity base of a new firm to 30 and we get the nominal capital using $K_{t}=\frac{A_{t}}{a_{t}}$.

In the first period all the firms are new, thus we set all the nominal equity base equal to 30 . Given the nominal interest rate, we are able to get the cost of the financing using (2), and we calculate the nominal capital the firm chooses and the production using (3) and the production function. Knowing the production we calculate the critical threshold of the relative price for each firm $\bar{u}_{i}$.

Now we get the relative price the firm take on the market by drawing from a uniform distribution $U[0,2]$. We drop the firm if its realization is less than its critical threshold. Using the value of $u_{i}$ we step the nominal equity base according to equation (4). Now we are ready to enter new firms. For determine the number we count the number of surviving firms and we multiply it for a number we draw from a normal distribution with mean 0.122 and standard deviation 0.03. The variable for the new entry are set in the way we described at the beginning of the appendix.

Now that firms exit and entry we perform the calculation: we determine the distribution of the equity ratio its mean and standard deviation. At this level we classify the firm with respect to their financial position in the following way. We set the level of a mean shock to $u=0.3$. We calculate $\bar{u}_{i}$ and than we classify a firm to be ponzi if its threshold is greater than 0.3 . Among the ponzi firms we check if their nominal equity base is less or equal to 30 , between 30 and 60 or grater than 60 to determine wether a ponzi firm is small, medium or big. Than we determine the nominal equity base each firm will have if it will be beaten by a mean shock using

$$
A_{i t}=A_{i t-1}+0.3 Y_{i}-r K_{i}-\frac{\gamma}{2} \frac{\left(K_{i}-K_{i t-1}\right)^{2}}{K}
$$

now we implement again the model and determine the hypothetical threshold for next period. We check again this value against the mean shock 0.3 if it's grater than this we classify a firm speculative and if it's less we classify the firm hedge. Like for the ponzi firms we analyze the firms' nominal equity base to classify them with respect to the size.

\section{References}

[1] Alchian A. A. (1950), "Uncertainty, Evolution and Economic Theory", Journal of Political Economy, LXIII, June. 
[2] Agliari, A., Delli Gatti, D., Gallegati, M. and Gardini, L. (1999), "Global Dynamics in a Non-linear Model of the Equity Ratio", Journal of Chaos, Solitons and Fractals, fortcoming.

[3] Baldwin, J. R. (1995). The Dynamics of Industrial Competition. Cambridge: Cambridge University Press.

[4] Bernanke B., M. Gertler, S. Gilchrist (1998), "The Financial Accelerator in Quantitative Business Cycle Framework", NBER Working Paper 6455 .

[5] Bernanke, B, and Gertler, M. (1989), "Agency Costs, net Worth and Business Fluctuations", American Economic Review, vol. 79, pp. 14-31.

[6] Caballero R., M. Hammour (1994), "The Cleansing Effect of Recessions", American Economic Review, 64, 1350-68.

[7] Caballero R.J., E.M. Engel, J.C. Haltinwanger (1997), "Aggregate Employment Dynamics: Building From Microeconomic Evidence", American Economic Review, 87, pp 115-37.

[8] Campbell J.R. (1997), "Entry, Exit, Embodied Technology, and Business Cycle", NBER working paper 5955.

[9] Caves R.E. (1998), "Industrial Organization and New Findings on the Turnover and the Mobility of Firms", Journal of Economic Literature, $36,1947-82$.

[10] Davis, S. T., J. C. Haltiwanger (1996), "Driving Forces and Employment Fluctuations: New Evidence and Alternative Fluctuations", NBER working paper 5775

[11] Davis, S. T., J. C. Haltiwanger, and S. Schuh (1996). Job creation amd Distruction. Cambridge, Mass.: MIT Press.

[12] Day, R. (1994), Complex Economic Dynamics, Cambridge (Mass.), MIT Press.

[13] Delli Gatti, D., Gallegati, M. and Minsky, H. (1996), "Financial Institutions, Economic Policy and the Dynamic Behavior of the Economy", 
in Helmstadter, E. and Perlman, M. (eds), Behavioral Norms, Technological Progress and Economic Dynamics, Ann Arbor, The University of Michigan Press.

[14] Delli Gatti, D.,Gallegati M., Palestrini, A. (1999), "Agents'Heterogeneity, Aggregation and Economic fluctuations", in Delli Gatti, D., Gallegati, M. and Kirman, A.P., eds., "Interaction and Market Structure", Springer, pp 133-149.

[15] Dosi, G., O. Marsili, L. Orsenigo, and R. Salvatore (1995). "Learning, Market Selection and the Evolution of Industrial Structures", Small Business Economics, 7, pp. 411-436.

[16] Dunne, T., M. J. Roberts, and L. Samuelson (1988). "Patterns of Firm Entry and Exit in U.S. Manufacturing Industries", Rand Journal of Economics, 19, pp. 495-515.

[17] Fazzari, S., Hubbard, G. and Petersen, B. (1988), "Financing Constraints and Corporate Investment", Brookings Papers on Economic Activity, I: 141-206.

[18] Fisher, I., 1933, "The Debt Deflation Theory of Great Depressions", Econometrica, 337-57.

[19] Fisher, J. (1996), "Credit Market Imperfections and the Heterogeneous Response of Firms to Monetary Shocks", Federal Reserve Bank of Chicago, working paper 96-23.

[20] Foster L., J.C. Haltinwanger, C.J. Crizan (1998), "Aggregate Productivity Growth: Lessons from Microeconomic Evidence", NBER Working Paper 6803.

[21] Gallegati M., L.Stanca (1999), "Financial Fragility, Heterogeneous Agents, and Aggregate Fluctuations: Evidence form a Panel of U.S. firms", Industrial and Corporate Change, fortcoming.

[22] Green W.H. (1997), Econometric Analysis, Prentice-Hall, Upper Saddle River.

[23] Greenwald, B.C., Stiglitz, J.E. (1988), "Imperfect Information, Finance Constraints and Business Fluctuations", in Kohn, M. and Tsiang, S.C. 
(eds.), Finance Constraints, Expectations and Macroeconomics, Oxford, Oxford University Press.

[24] Greenwald, B.C., Stiglitz, J.E. (1990), "Macroeconomic Models with Equity and Credit Rationing", in Hubbard, R. G. (ed.), Financial Markets and Financial Crises, Chicago, Chicago University Press.

[25] Greenwald, B.C., Stiglitz, J.E. (1993), "Financial Market Imperfections and Business Cycles", Quarterly Journal of Economics, vol. 108, pp. 77-114.

[26] Hahn, F. and Solow, R. (1995), An Essay in Modern Macroeconomic Theory, Cambridge, MIT Press.

[27] Hicks, J.R. (1950), A Contribution to the Theory of the Trade Cycle, Oxford Clarendon.

[28] Hopenhayn, H. (1992). "Entry, Exit and Firm Dynamics in Long Run Equilibrium", Econometrica, 60, pp. 1127-1150.

[29] Judd, J. P. and B. Treham (1995). "The Cyclical Behaviour of Prices. Interpreting the Evidence", Journal of Money, Credit and Banking, 27, pp. 789-797.

[30] Keynes, J.M. (1931), "The consequences to the banks of the collapse of money values", in the Collected Works of J.M.Keynes, ed. by D.Moggridge, vol.IX: 150-60, London: Macmillan.

[31] Klepper, S. (1996), Entry, Exit, Growth, and Innovation over the Product Life Cycle, American-Economic-Review, 86(3), pp. 562-83.

[32] Lucas, R.E. (1977), "Understanding Business Cycles", in D. Brunner, A.H: Meltzer, eds, Stabilization of Domestic and International Economy, Amsterdam, North Holland.

[33] Minsky, H.P. (1954), Induced Investment and Business Cycle, Unpublished Ph.D. Thesis.

[34] Minsky, H.P. (1957) "Monetary Systems and Accelerator Models" American Economic Review 
[35] Minsky, H.P. (1986), Stabilizing an Unstable Economy, New Haven, Yale University Press.

[36] Pigou A.C. (1928), "An Analysis of Supply", Economic Journal, 28, 238-57.

[37] Rahn R.J., (1985), "Aggregation in System Dynamics", System Dynamic Review, 1, 111-22.

[38] Reichlin P., P.Siconolfi (1998), "Adverse Selection of Investment Projects and the Business Cycle", Temi di discussione 326, Banca d'Italia, Roma.

[39] Stanca L., D.Delli Gatti and M.Gallegati (1998), "Financial fragility, heterogeneous agents, and aggregate fluctuations: evidence from a panel of U.S. firms", Applied Financial Economics, 21 (9), 87-99.

[40] Sutton, J. (1997). "Gibrat's Legacy", Journal of Economie Literature, 35 , pp. 40-59.

[41] Temin P. (1998), "The Causes of Americam Business Cycle: an Essay in Economic Historiography", in "beyond shocks: what causes business cycle", Fuhrer J.C. and S. Schuh, eds., conference series, n. 42, federal reserve bank of boston, 37-59.

[42] Teräsvirta, T., Lundbergh, S. (1998), "Modeling Economic HighFrequency Time Series with STAR-STGARCH Models", SSE/EFI working paper n. 291, Stockholm.

[43] Zarnowitz V. (1998). "Has the Business Cycle Been Abolished?", Business Economics, 33, 39-45.

[44] Williamson S.D. (1996), "Real Business Cycle research comes of age", Journal of Monetary Economics, 38, 161-70.

[45] Winter, S. G., Y. M. Kaniovski, and G. Dosi (1997). A Baseline Model of Industry Evolution. Interim Report 111-97-013/March, International Institute for Applied Systems Analysis, Luxenburg, Austria. 